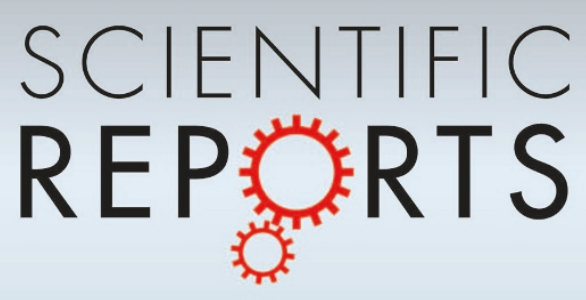

OPEN

SUBJECT AREAS:

SYNTHESIS OF

GRAPHENE

DESIGN, SYNTHESIS AND PROCESSING

SOLAR CELLS

SYNTHESIS AND PROCESSING

Received

10 June 2013

Accepted

12 September 2013

Published

8 October 2013

Correspondence and requests for materials should be addressed to

B.R.M. (brmehta@ physics.iitd.ac.in)

\section{In-flight gas phase growth of metal/multi layer graphene core shell nanoparticles with controllable sizes}

\author{
Saurabh K. Sengar' , B. R. Mehta' ${ }^{1}$, Rakesh Kumar' \& Vinod Singh ${ }^{1,2}$ \\ 'Thin Film Laboratory, Indian Institute of Technology New Delhi, India-1 10016, '2Department of Applied Physics, Delhi \\ Technological University, Delhi, India-1 10042.
}

In this report, we present a general method for a continuous gas-phase synthesis of size-selected metal/multi layer graphene (MLG) core shell nanoparticles having a narrow size distribution of metal core and MLG shell for direct deposition onto any desired substrate kept under clean vacuum conditions. Evolution of MLG signature is clearly observed as the metal-carbon agglomerates get transformed to well defined metal/ MLG core shell nanoparticles during their flight through the sintering zone. The growth takes place via an intermediate state of alloy nanoparticle (Pd-carbon) or composite nanoparticle (Cu-carbon), depending upon the carbon solubility in the metal and relative surface energy values. It has been also shown that metal/ MLG nanoparticles can be converted to graphene shells. This study will have a large impact on how graphene or graphene based composite nanostructures can be grown and deposited in applications requiring controllable dimensions, varied substrate choice, large area and large scale depositions.

The

he observation of unique combination of properties, such as, mechanical strength, good thermal and electronic conductivity, zero band gap and ballistic electron transport in the 'ideal two dimensional' graphene structure have resulted in an unprecedented research interest ${ }^{1-6}$. In the last few years, graphene-metal nanoparticle composites have got attention due to possibility of tailoring the above mentioned properties resulting in improved, new and novel applications ${ }^{7-18}$. State of the art chemical vapor deposition allows the growth of graphene sheets on metal foils ${ }^{19}$. The restrictions of graphene growth only on few selected metal substrates and the requirement of transfer are the main nagging issues for using the graphene-metal nanostructures prepared by the above method in applications requiring large scale and large area deposition such as catalysis, Li ion batteries and solar cells $s^{7-9,14,20}$. The multistep chemical processes, used for growing graphene-metal composites involve simultaneous or separate reduction of graphene oxide with metal precursors yielding undefined configurations, high dispersibility and wide distribution of nanoparticle sizes and graphene thickness ${ }^{21}$. Chemical contamination incorporated into metal nanoparticles and graphene layers during reduction process is known to affect optical, electronic and catalytic properties ${ }^{22-24}$. The average nanoparticle size and distribution of Au nanoparticles grown by physical vapor deposition methods is linked to the number of graphene layer ${ }^{25,26}$. In physical methods of metal nanoparticles deposition, both particle density and particle size depend upon deposition time, and thus, nanoparticle size cannot be controlled independently. Further, in earlier reports on metal- carbon core shell nanoparticles prepared by arc discharge, metal carbide (in place of metal) core was found to be encapsulated in polyhedron carbon shell $\mathrm{s}^{27}$. In another report, the graphite layer surrounding the metal nanoparticle was found to appear throughout the sample ${ }^{28}$. Broad size distribution and phase inhomogeneity are the other issues in these metal/graphite core shell nanoparticle prepared by arc discharge method ${ }^{27,28}$. Metal/graphite nanoparticles prepared by chemical methods have been reported to have low crystallinity, chemical contamination, and broad size distribution ${ }^{29,30}$. Therefore, these methods are not suitable for applications requiring controllable size, narrow size distribution and well defined graphene-metal interface such as biomedical and opto-electronic applications. In this report, a gas phase synthesis methodology for growing size selected metal/multilayer graphene (M/MLG) core shell nanoparticles with controllable size, narrow size distribution, well defined metal core and graphene shell is described.

\section{Results}

M/MLG core shell nanoparticles were fabricated using an integrated gas phase synthesis setup of which schematic diagram is shown in Fig. 1. The structural properties of the nanoparticles sintered at different temperatures during 


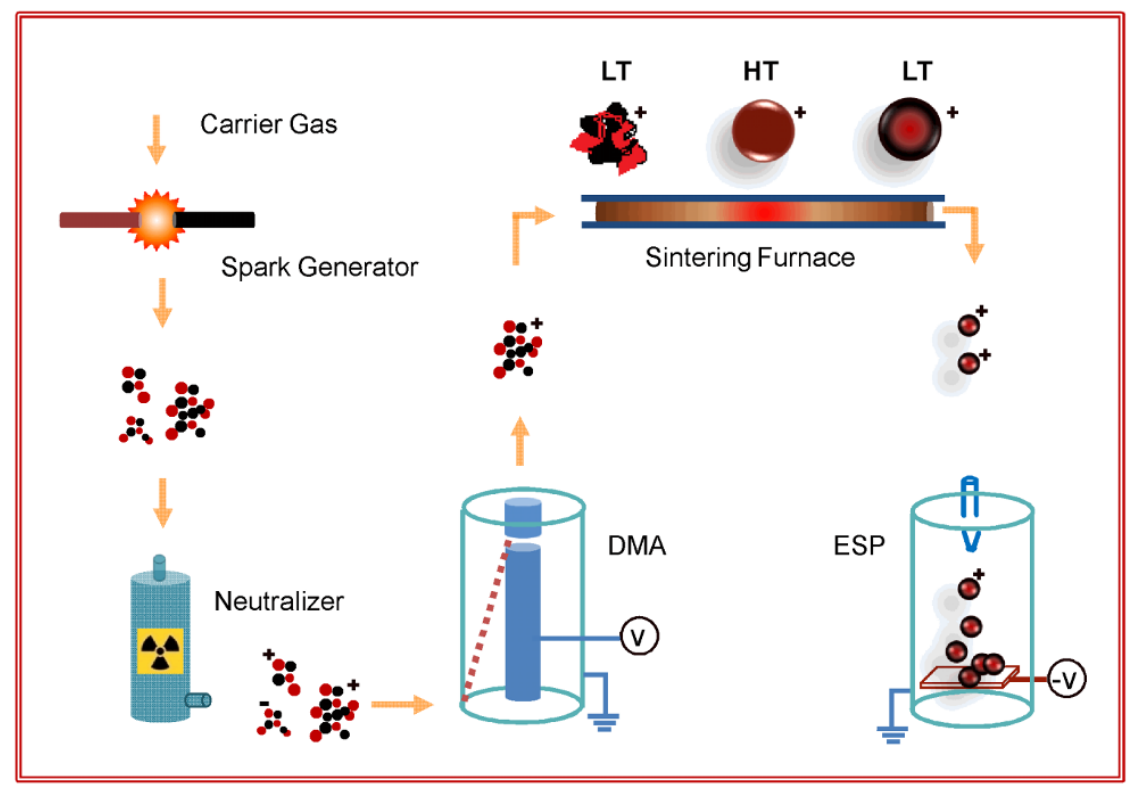

Figure 1 Synthesis Methodology. Integrated gas phase synthesis setup for the growth of graphene-metal nanoparticles comprising of carrier gas assisted nanoparticle journey starting with formation of metal-carbon agglomerates in the spark generator, charging in the neutralizer, size selection in the DMA, sintering and subsequent cooling in the sintering furnace and deposition on desired substrate in the ESP as the final step. LT-low temperature, HT-High temperature zones.

in-flight sintering were carried out using glancing angle $\mathrm{x}$-ray diffraction (GAXRD). GAXRD diffractograms of the Pd-C nanoparticles sintered at different temperatures are shown in Fig. 2a. The unsintered Pd-C agglomerates show high intensity peak at $2 \theta$ (dvalue) of $39.36^{\circ}(2.287 \AA)$ corresponding to Pd-C solid solution in face centered cubic (FCC) phase having carbon atoms at interstitial positions ${ }^{31}$. In addition, a relatively low intensity peak at $40.04^{\circ}$ (2.250 $\AA$ ) corresponding to Pd FCC phase is also evident. A lattice parameter of $2.309 \AA$ is reported in Pd-C nanoparticles due to the incorporation of carbon at the interstitial positions ${ }^{31}$. This behavior is similar to that observed in case of $\mathrm{Pd}-\mathrm{H}$ system where hydrogen incorporation at the interstitial positions results in lattice expansion due to formation of $\beta$-palladium hydride phase ${ }^{32}$. In nanoparticles sintered at $300^{\circ} \mathrm{C}$ and deposited at RT, intensity of the $\mathrm{Pd}$ peak increases, accompanied by a decrease in Pd-C peak intensity and shift towards higher $2 \theta$ value. On further increasing the sintering temperature to $500^{\circ} \mathrm{C}$, intensity of the Pd peak becomes higher than that of the Pd-C peak indicating that more and more of the carbon phase segregates out as the sintering temperature is increased. Finally, in nanoparticles sintered at $700^{\circ} \mathrm{C}$, only $\mathrm{Pd}$ peak is observed with nearly complete segregation of carbon phase out of the $\mathrm{Pd}$ lattice. Unlike, Pd-C system, XRD peaks corresponding to the FCC $\mathrm{Cu}$ phase remains unchanged in all the samples sintered at different temperatures and stay at $43.275^{\circ}(2.090 \AA)$, as shown in Fig. 2b. This indicates that small carbon solubility has negligible effect on $\mathrm{Cu}$ lattice.

Morphological changes in $\mathrm{Pd}-\mathrm{C}$ and $\mathrm{Cu}-\mathrm{C}$ nanoparticles on sintering were studied using high resolution electron microscopy (HRTEM). HRTEM micrographs of the Pd-C nanoparticles sintered at different temperatures are shown in Figs. 3a-d (also see supplementary Fig. S1). It is clear from Fig. 3a that the initial agglomerates consist of $2-5 \mathrm{~nm}$ sized primary nanoparticles as revealed by lattice fringes $(2.390 \AA)$ corresponding to Pd-C alloy. On increasing the sintering temperature to $300^{\circ} \mathrm{C}$, particles start merging as compaction process is initiated (Fig. 3b). Thereafter, at a sintering temperature of $500^{\circ} \mathrm{C}$, compact, quasi-spherical and crystalline nanoparticles having carbon layers in the shell around the inner core are formed (Fig. 3c). Finally, sintering at $700^{\circ} \mathrm{C}$ results in the formation of nearly spherical, $\mathrm{Pd} / \mathrm{C}$ core shell nanoparticles with carbon shell clearly visible in the HRTEM image (Fig. 3d). In the Pd/C core shell nanoparticle sintered
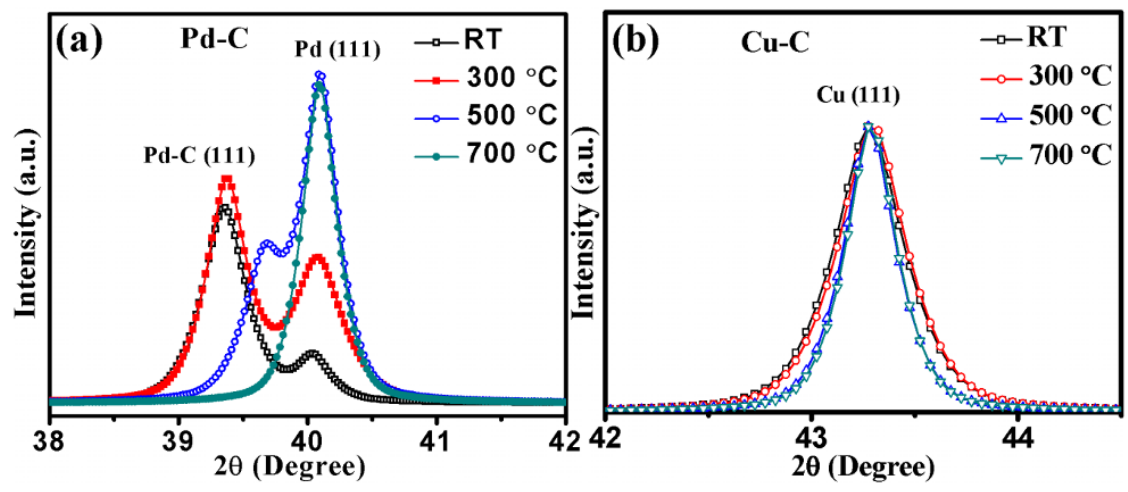

Figure $2 \mid$ Effect of in-flight sintering on structural properties. (a) X-ray diffractograms of Pd (111) peak show that initial Pd-C agglomerates get converted to Pd-C alloy nanoparticles before the segregation of carbon on surface of Pd nanoparticle core. (b) X-ray diffractograms of Cu-C do not show any lattice expansion indicated by $\mathrm{Cu}(111)$ peak due to very low solubility of carbon into $\mathrm{Cu}$. 


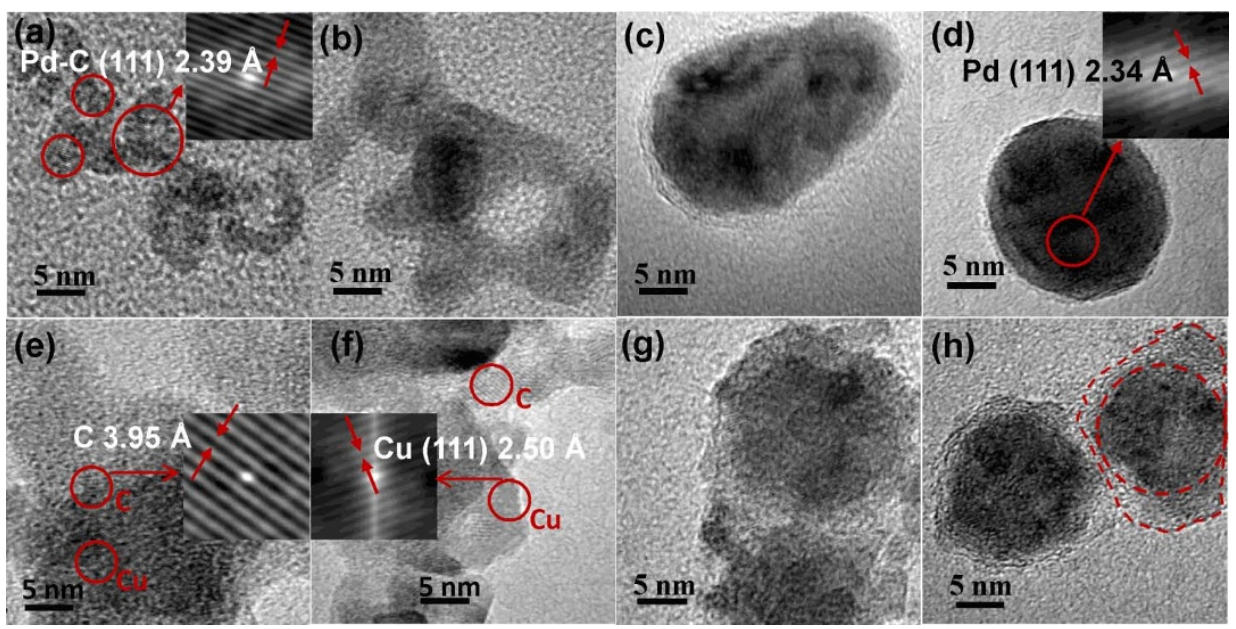

Figure 3 Morphological changes on in-flight sintering. TEM images showing the compaction and conversion of (a-d) Pd-C and (e-h) Cu-C agglomerates to Pd/MLG and Cu/MLG core shell nanoparticles on sintering. HRTEM image of Pd-C agglomerates (a) showing Pd-C phase which gets converted to Pd phase (d) in the nanoparticle core on sintering at $700^{\circ} \mathrm{C}$ followed by subsequent cooling. MLG shell around the well formed metal nanoparticles is clearly visible in Figs. $\mathrm{c}$ and d. HRTEM images (e-f) of $\mathrm{Cu}-\mathrm{C}$ nanoparticles show the presence of both $\mathrm{Cu}$ and $\mathrm{C}$ phases as confirmed by lattice fringes of selected regions in the micrographs (inset of e and f). Graphene shell layer around the well formed metal nanoparticles is clearly visible in Fig. g and h.

at $700^{\circ} \mathrm{C}$ a d-value of $2.340 \AA$ is obtained from the lattice fringes of the $\mathrm{Pd}$ nanoparticle-core. The $\mathrm{d}$-values of $\mathrm{Pd}-\mathrm{C}$ and $\mathrm{Pd}$ phases using TEM are larger in comparison to those calculated from XRD. Slightly larger value of $\mathrm{d}$-spacing as calculated by TEM in comparison to XRD may be due to the localized measurement in electron diffraction technique and a possibility of lattice expansion at smaller sizes ${ }^{33-35}$. The d-value obtained from XRD is the average value calculated from a larger sample having widely varying sizes of clusters especially in unsintered samples while the d-value obtained from HRTEM measurement corresponds to a specific nanoparticle. A large change in the lattice constant has been reported in a number of material systems $^{34,35}$. Similar trends in the morphological changes of $\mathrm{Cu}-\mathrm{C}$ nanoparticle system during the conversion of $\mathrm{Cu}-\mathrm{C}$ agglomerates to $\mathrm{Cu} / \mathrm{C}$ core shell nanoparticles are observed. In the HRTEM images (Figs. 3e-h) lattice fringes with inter-planar spacing of $3.95 \AA$ and $2.50 \AA$ are observed at different locations in case of agglomerated Cu$\mathrm{C}$ particles. These values differ with the corresponding bulk values of $3.40 \AA$ and $2.09 \AA$ for graphite and Cu, respectively. These differences may be due to lattice expansion at smaller sizes of metal and carbon clusters in the agglomerates at $\mathrm{RT}^{34,35}$. Again the difference between the d-value of $\mathrm{Cu}$ calculated from XRD and HRTEM may be due to the localized measurement in HRTEM and widely varying cluster sizes in unsintered samples. On sintering at a temperature of $300^{\circ} \mathrm{C}$, the compaction process gets initiated as shown in Fig. $3 \mathrm{f}$.
At $500^{\circ} \mathrm{C}$ sintering, formation of the $\mathrm{Cu}$ nanoparticle core and carbon shells is initiated (Fig. 3g). On further increasing the sintering temperature to $700^{\circ} \mathrm{C}$ quasi spherical metal nanoparticle core enveloped by well formed carbon shell around them is clearly observed in the HRTEM micrograph (Fig. 3h).

To investigate the nature of carbon, micro- Raman measurements of $\mathrm{Cu}-\mathrm{C}$ and $\mathrm{Pd}-\mathrm{C}$ nanoparticles sintered at different temperatures were carried out and are shown in Figs. $4 a$ and b, respectively. In the initial $\mathrm{Cu}-\mathrm{C}$ and $\mathrm{Pd}-\mathrm{C}$ agglomerates without any sintering, no Raman peak in the entire measurement range of $1100-3200 \mathrm{~cm}^{-1}$ is observed. In the unsintered samples, carbon is present in the form of amorphous and nanosized carbon clusters or Pd-C clusters which are loosely connected to form agglomerates. A significant portion of carbon is present in the form of $\mathrm{Pd}-\mathrm{C}$ and is expected not to show any $D$ and $G$ peak. In an earlier report, similar results on the absence of Raman $D$ and $G$ peaks in unsintered Ti-B-C films have been reported ${ }^{36}$. G peak is due to the relative motion of $\mathrm{sp}^{2}$ carbon atoms while $\mathrm{D}$ peak is linked to the breathing mode of carbon rings (defects) ${ }^{37}$. As shown in Fig. $4 a, G$ peak lie at $1584 \mathrm{~cm}^{-1}$ and $\mathrm{I}_{\mathrm{D}} / \mathrm{I}_{\mathrm{G}}$ ratio is found to be 0.73 in the $\mathrm{Cu}-\mathrm{C}$ nanoparticles sintered at $300^{\circ} \mathrm{C}$. These values of $\mathrm{G}$ peak and $\mathrm{I}_{\mathrm{D}} / \mathrm{I}_{\mathrm{G}}$ ratio correspond to either amorphous carbon or nanocrystalline graphite ${ }^{37}$. The absence of second order $2 \mathrm{D}$ peak which is the second order overtone of $\mathrm{D}$ peak in $\mathrm{Cu}-\mathrm{C}$ samples sintered at $300^{\circ} \mathrm{C}$ indicates that it is amorphous
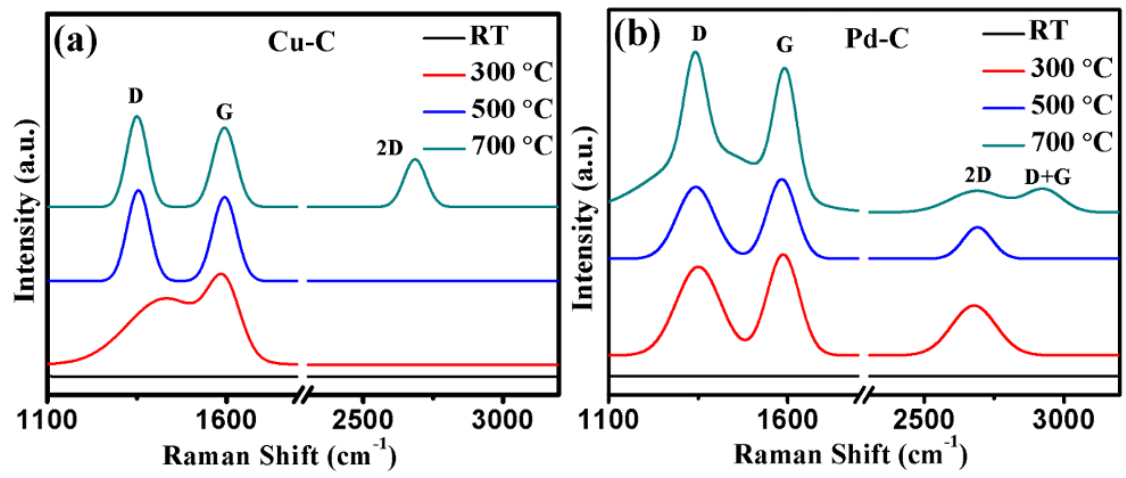

Figure $4 \mid$ Effect of sintering on Raman properties. Raman spectra of (a) $\mathrm{Cu}-\mathrm{C}$ and (b) $\mathrm{Pd}-\mathrm{C}$ nanoparticles sintered at increasing temperatures show that the initial amorphous carbon gets converted to MLG on sintering at $700^{\circ} \mathrm{C}$. 
carbon and not nanocrystalline graphite $\mathrm{e}^{37,38}$. The possibility of diamond like carbon instead of amorphous carbon has been ruled out as the $\mathrm{I}_{\mathrm{D}} / \mathrm{I}_{\mathrm{G}}$ ratio is $>0.2^{37}$. On increasing the sintering temperature to $500^{\circ} \mathrm{C}, \mathrm{G}$ peak appears at $1594 \mathrm{~cm}^{-1}$ while the $\mathrm{I}_{\mathrm{D}} / \mathrm{I}_{\mathrm{G}}$ ratio increases to 1.08 in $\mathrm{Cu}-\mathrm{C}$ nanoparticles. Finally on sintering at $700^{\circ} \mathrm{C}, \mathrm{G}$ peak remains constant and $\mathrm{I}_{\mathrm{D}} / \mathrm{I}_{\mathrm{G}}$ ratio increases to 1.15 in $\mathrm{Cu}-\mathrm{C}$ nanoparticles. Further, in $\mathrm{Cu}-\mathrm{C}$ nanoparticles sintered at $700^{\circ} \mathrm{C}, 2 \mathrm{D}$ peak appears at $2685 \mathrm{~cm}^{-1}$. According to the 3-stage theory, $\mathrm{G}$ peak position near to $1600 \mathrm{~cm}^{-1}$ and a continuous increase in $\mathrm{I}_{\mathrm{D}} / \mathrm{I}_{\mathrm{G}}$ ratio indicates that amorphous carbon gets converted to nanocrystalline graphite on increasing the sintering temperature ${ }^{38,39}$. Further, in $\mathrm{Cu}$ $\mathrm{C}$ nanoparticles sintered at $700^{\circ} \mathrm{C}, \mathrm{I}_{\mathrm{G}} / \mathrm{I}_{2 \mathrm{D}}$ ratio is found to be 1.66 while in bulk graphite $\mathrm{I}_{\mathrm{G}} / \mathrm{I}_{2 \mathrm{D}}$ ratio is reported to be $\sim 4$ which indicates that it is not nanocrystalline graphite but a stack of graphene nanolayers (MLG). As per literature, $\mathrm{I}_{\mathrm{G}} / \mathrm{I}_{2 \mathrm{D}}$ ratio of 1.66 represents a stack of 4-5 graphene nanolayers ${ }^{40}$. HRTEM micrograph (Fig. 3h) of $\mathrm{Cu}-\mathrm{C}$ nanoparticles sintered at $700^{\circ} \mathrm{C}$ confirms this.

In $\mathrm{Pd}-\mathrm{C}$ nanoparticles sintered at $300^{\circ} \mathrm{C}$, three peaks at $1351 \mathrm{~cm}^{-1}, 1586 \mathrm{~cm}^{-1}$, and $2678 \mathrm{~cm}^{-1}$ corresponding to $\mathrm{D}, \mathrm{G}$ and $2 \mathrm{D}$ bands, respectively, are observed. In these nanoparticles, $\mathrm{I}_{\mathrm{G}} / \mathrm{I}_{2 \mathrm{D}}$ ratio is 2.05 and $\mathrm{I}_{\mathrm{D}} / \mathrm{I}_{\mathrm{G}}$ ratio is 0.87 . As discussed earlier, these conditions correspond to nanocrystalline graphite. On increasing the sintering temperature to $500^{\circ} \mathrm{C}, \mathrm{I}_{\mathrm{G}} / \mathrm{I}_{2 \mathrm{D}}$ ratio increases to 2.41 while $\mathrm{I}_{\mathrm{D}} / \mathrm{I}_{\mathrm{G}}$ ratio remains nearly same at 0.91 . Finally at $700^{\circ} \mathrm{C}, \mathrm{I}_{\mathrm{G}} / \mathrm{I}_{2 \mathrm{D}}$ ratio increases to 6.69 and $\mathrm{I}_{\mathrm{D}} / \mathrm{I}_{\mathrm{G}}$ ratio increases to 1.11 .

One of the advantages of the integrated gas phase deposition is that nanoparticle growth and deposition on to substrates are two independent steps. Nanoparticles having a controllable size and narrow size distribution can be grown by controlling the electrical mobility, which in turn can be changed by aerosol flow rate and DMA voltage. Size selected $\mathrm{Cu} / \mathrm{MLG}$ core shell nanoparticles having an initial mobility equivalent diameter $(\mathrm{Dm})$ of 68,52 , and $35 \mathrm{~nm}$ were grown using proper sintering conditions. It needs to be mentioned here that smaller mobility diameter particles require lower sintering temperature consistent with the normally observed depression in the melting point at lower sizes. It is observed from the HRTEM images in Figs. $5 \mathrm{a}$ and $5 \mathrm{~b}$ that nanoparticle core is spherical and has a very well defined size $(\mathrm{Dg})$ of $29.9 \pm 2.9,21.9 \pm 1.7$ and $18.3 \pm 1.4 \mathrm{~nm}$ in the sintered Cu/MLG core shell nanoparticles (see supplementary Figs. $\mathrm{S} 2$ and S3). In $\mathrm{Cu} / \mathrm{MLG}$ core shell nanoparticles having $\mathrm{D}_{\mathrm{m}}=35 \mathrm{~nm}$, the average size of the $\mathrm{Cu}$ core and the thickness of the MLG shell are $14.5 \pm 0.9 \mathrm{~nm}$ and $2.3 \pm 0.6 \mathrm{~nm}$, respectively, as shown in the size histograms in Fig. 5c. In case of Pd/MLG samples too, nearly same values of sizes are observed (supplementary Figures S2 and S3). From the comparison of HRTEM micrographs of Pd/MLG and Pd (without any carbon) nanoparticles it is clear that unlike Pd/MLG, Pd nanoparticles don't have any MLG like shell structure (supplementary Fig. S2). With increase in the size of the nanoparticle core, the width of the graphene shell is observed to decrease. This may be due to the difference in solubility of carbon in metal nanoparticle of different sizes. The Raman spectra of size selected core shell $\mathrm{Cu} /$ MLG nanoparticles having Dm values of 35, 52 and $68 \mathrm{~nm}$ is shown in Fig. $5 \mathrm{~d}$. The $\mathrm{I}_{\mathrm{G}} / \mathrm{I}_{2 \mathrm{D}}$ ratio for the $\mathrm{Cu} / \mathrm{MLG}$ nanoparticles having $\mathrm{Dm}$ values of 35,52 and $68 \mathrm{~nm}$ comes out to be 1.66, 1.49 and 0.79 , respectively. As discussed earlier, this indicates that properly sintered spherical shaped $\mathrm{Cu} / \mathrm{C}$ nanoparticles have a shell comprising of multi
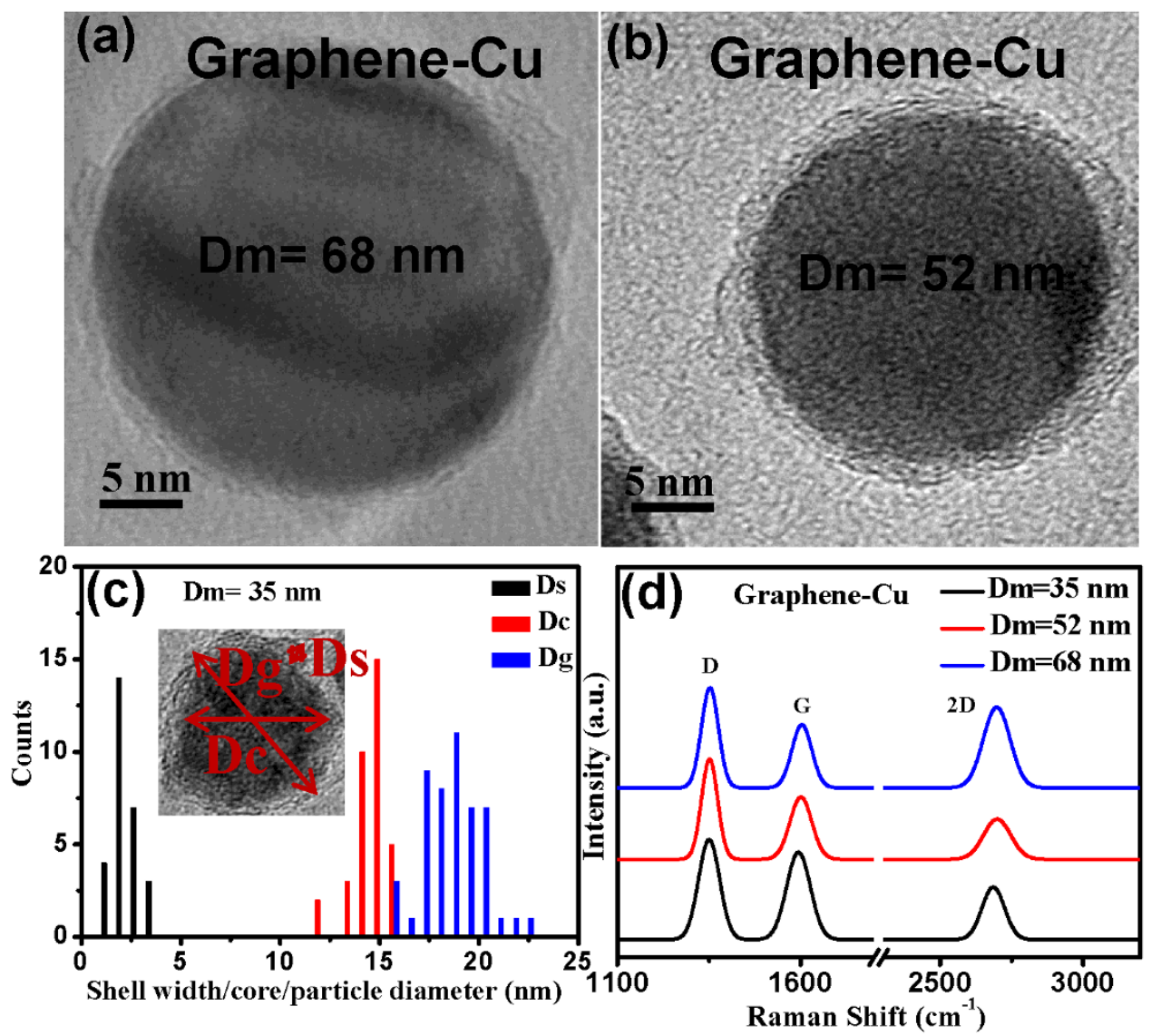

Figure 5 Size selected Cu/MLG nanoparticles. [(a), (b)] HRTEM micrographs of Cu/MLG nanoparticles with mobility equivalent diameter (Dm) of 68 and $52 \mathrm{~nm}$, respectively. (c) Histogram showing size distribution of shell thickness (Ds), Core diameter (Dc) and nanoparticle size (Dg) for Cu/MLG nanoparticle having Dm $=35 \mathrm{~nm}$. Narrow size distribution, control of nanoparticle size by controlling electrical mobility diameter and well formed nanoparticle core and graphene shell are clearly visible. (d) Raman Spectra of size selected Cu/MLG nanoparticles for Dm = 35, 52 and $68 \mathrm{~nm}$ showing decrease in graphene layers with increase in nanoparticle size. 

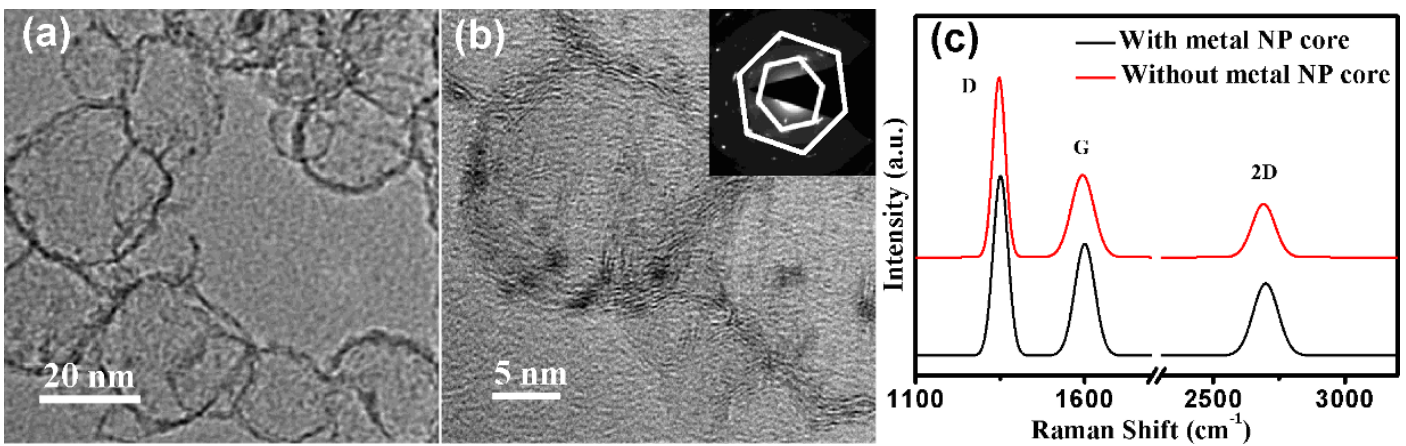

Figure 6 | Graphene nanoshells. [(a), (b)] HRTEM images of MLG shells formed by removing metal core via chemical etching. Inset shows SAED diffraction pattern of the MLG shells. (c) Comparison of Raman spectrum with and without Cu nanoparticle (NP) core confirms the preservation of MLG shell on chemical etching.

layer graphene. The continuously decreasing $\mathrm{I}_{\mathrm{G}} / \mathrm{I}_{2 \mathrm{D}}$ ratio indicates that the number of graphene nanolayers decrease on increasing the particle size. Decrease in number of graphene layers on increasing the Dm value is consistent with HRTEM of Cu/MLG core shell nanoparticles.

Wet chemical etching was used to remove the metal core in order to obtain the MLG shells (Fig. 6a) from the Cu/MLG core shell nanoparticles using $\mathrm{FeCl}_{3}$ solution. After chemical etching MLG shell structures consisting of about 3-4 graphene layers can be easily seen in the HRTEM image (Fig. 6b). The selected area electron diffraction (SAED) patterns (Fig. 6b) with six fold symmetry confirm the MLG shell structure after removing the metal core. The Raman spectrum (Fig. 6c) shows an increase in $\mathrm{I}_{\mathrm{D}} / \mathrm{I}_{\mathrm{G}}$ peak ratio from 1.59 to 2.18 after etching the $\mathrm{Cu}$ from the nanoparticle core which may be due to defects created during etching. To show the universality of the present method to spray coat the M/MLG nanoparticles onto any desired substrate, Cu/MLG core shell nanoparticles were deposited on to $\mathrm{Si}$ (polished and textured) and interdigitated $\mathrm{Au}$ electrodes ( $\mathrm{Au}-\mathrm{Cr} / \mathrm{SiO}_{2} / \mathrm{Si}$ ). Scanning electron microscopy (SEM) images of $\mathrm{Cu} / \mathrm{MLG}$ nanoparticles $(\mathrm{Dm}=52 \mathrm{~nm}$ ) grown on polished $\mathrm{Si}$, textured $\mathrm{Si}$ and interdigitated $\mathrm{Au}$ electrodes fabricated on $\mathrm{SiO}_{2} / \mathrm{Si}$ substrates are shown in Figs. 7a-c. Optical and electronic properties of the $\mathrm{Cu} / \mathrm{MLG}$ nanoparticles were also studied. Reflectance spectrum of $\mathrm{Cu} / \mathrm{MLG}$ nanoparticles $(\mathrm{Dm}=52 \mathrm{~nm}$ ) deposited on polished $\mathrm{Si}$ is shown in Fig. 7a (inset). Reflectance spectrum of Cu/MLG nanoparticles deposited on polished $\mathrm{Si}$ shows a large drop in total reflectance in comparison to the bare $\mathrm{Si}$. Electronic properties of $\mathrm{Cu} / \mathrm{MLG}$ nanoparticles were carried out in a field effect transistor (FET) structure where n-doped Si substrate is acting as back gate. The source-drain resistance versus back-gate voltage $V_{B G}$ curve for the $\mathrm{Cu} / \mathrm{MLG}$

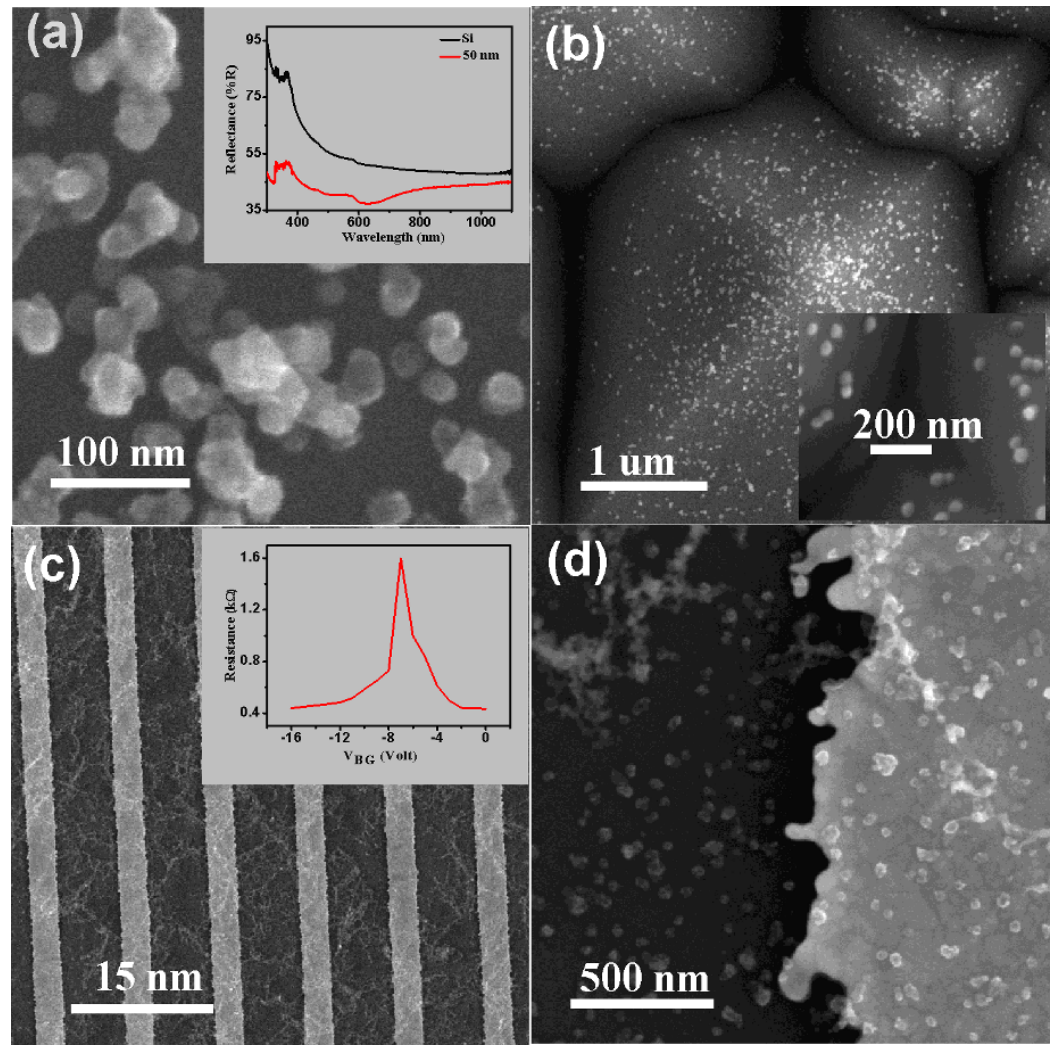

Figure $7 \mid$ Direct deposition of Cu/MLG core shell nanoparticles on substrates having different morphologies. SEM images of Cu/MLG nanoparticle $(\mathrm{Dm}=50 \mathrm{~nm})$ deposited on (a) polished, (b) textured Si substrates and (c, d) interdigitated Au electrodes. Inset of (a) shows the comparison of the reflectance spectra of $\mathrm{Cu} / \mathrm{MLG}$ nanoparticle on $\mathrm{Si}$ and bare Si substrate. Inset of (c) shows gate voltage characteristics of Cu/MLG nanoparticles deposited in FET structure. 
nanoparticles at room temperature is shown in Fig. 7c (inset). Dirac point at a negative gate voltage indicates unintentional $n$-type doping of the $\mathrm{Cu} / \mathrm{MLG}$ nanoparticles ${ }^{41}$.

\section{Discussion}

On the basis of the results of the structural, morphological and Raman studies, formation of M/MLG core shell nanoparticles in both the $\mathrm{Pd}-\mathrm{C}$ and $\mathrm{Cu}-\mathrm{C}$ material systems can be understood in terms of temperature dependence of carbon solubility in metals and the relative surface energy values. The solubility of carbon in different metals forming solid solution is given by the following equation based on Henrian behavior for the carbon activity ${ }^{42}$.

$$
\frac{x_{c}}{1-2 x_{c}}=\exp \left(-\frac{\Delta H}{R T}\right) \exp \left(\frac{\Delta S}{R}\right)
$$

Where $x_{c}$ is the carbon content in mole fraction, $\Delta H$ is the partial molar enthalpy of carbon in solution, $\Delta S$ is the partial molar excess enthalpy of carbon in solutions, $R$ is the gas constant and $T$ is the absolute temperature. Using the reported values of $\Delta H(-30.9 \mathrm{~kJ} /$ $\mathrm{mol})$ and $\Delta S(-0.136 \mathrm{R})$ an increase from $3 \mathrm{ppm}$ at RT to $15800 \mathrm{ppm}$ at $700^{\circ} \mathrm{C}$ of carbon solubility in Pd lattice is calculated ${ }^{43}$. Observed shift (Fig. 2a) in XRD peak positions of Pd indicate that Pd-C solid solution is formed in the intermediate growth stage. Carbon solubility in $\mathrm{Cu}$ at $\mathrm{RT}$ and $700^{\circ} \mathrm{C}$ is calculated to be $1.5 \times 10^{-4} \mathrm{ppm}$ and $2.5 \mathrm{ppm}$, respectively, using the reported values of $\Delta H(-35.1 \mathrm{~kJ} /$ $\mathrm{mol})$ and $\Delta S(-8.532 \mathrm{R})^{42}$. Due to low carbon solubility in copper, no change in the XRD peak positions of the $\mathrm{Cu}$ (Fig. 2b) is observed in $\mathrm{Cu}-\mathrm{C}$ system. Average surface energy of carbon in different phases (fullerene, graphite, and carbon black) is quite low $\left(<250 \mathrm{~mJ} / \mathrm{m}^{2}\right)$ in comparison to $\mathrm{Pd}\left(2.05 \mathrm{~J} / \mathrm{m}^{2}\right)$ and $\mathrm{Cu}\left(1.83 \mathrm{~J} / \mathrm{m}^{2}\right)^{44,45}$. In Pd-C system, a solid solution of $\mathrm{Pd}-\mathrm{C}$ is formed on sintering, higher the sintering temperature more is the carbon solubility. As particles come out of the sintering zone, temperature decreases and hence carbon atoms segregate out of the Pd lattice and migrate to surface due to their low surface energy. Lattice fringes corresponding to Pd$\mathrm{C}$ and $\mathrm{Pd}$ (Figs. $3 \mathrm{e}$ and $3 \mathrm{~h}$ ) are observed in unsintered agglomerates and nanoparticles sintered at $700^{\circ} \mathrm{C}$, respectively. In case of $\mathrm{Cu}-\mathrm{C}$ system, initially agglomerates consist of copper and carbon primary particles. At high temperatures $\mathrm{Cu}-\mathrm{C}$ composite nanoparticle having $\mathrm{Cu}, \mathrm{C}$ and mixed phases are formed, as confirmed by lattice fringes in the HRTEM images (Figs. 3a and 3b) of unsintered agglomerates and sintered agglomerates at $300^{\circ} \mathrm{C}$. As $\mathrm{Cu}-\mathrm{C}$ composite nanoparticle is sintered at higher temperature carbon segregates to the outer surface due to lower surface energy value while $\mathrm{Cu}$ segregates to the inner core. As both sintering and cooling takes place in-flight in the homogeneous gaseous medium, quasi spherical nanoparticles having $\mathrm{Pd} /$ $\mathrm{Cu}$ core and MLG shell are formed. It is necessary to mention that in both the material systems optimized sintering temperature is important for the growth of MLG shell around the spherical metal nanoparticle core. Under-sintering leads to incomplete compaction while over-sintering is observed to result in re-evaporation of metallic phases, both of which affect the size and size distribution of metal core and MLG shells. Large solubility values of $\mathrm{C}$ in $\mathrm{Fe}, \mathrm{Co}$ and $\mathrm{Ni}$ at higher temperatures and large surface energy values of most of the metals (e.g. Pt, Ni, Co, W, Fe, Cr, and Ti) in comparison to carbon allows this method to be used as a general technique for M/MLG core shell nanoparticle growth ${ }^{46}$. Controlled growth of M/MLG core shell nanoparticles having a well defined size and narrow size distribution can be achieved by just manipulating the solubility and surface energy of two components with in-flight sintering temperature.

Gas phase deposition methods are ideally suitable for large scale and continuous deposition ${ }^{47}$. Recent report on the continuous growth of semiconductor nanorods onto size selected seed nanoparticles is a novel demonstration of the versatility of the gas phase deposition methods. A careful control of homogenous (Au nanoparticle) and heterogeneous nucleation ( $\mathrm{GaAs}$ nanorods onto $\mathrm{Au}$ ) in the gas has been utilized to grow $\mathrm{Au}-\mathrm{GaA}$ s nanostructures ${ }^{47}$. The present method is a major step forward towards the advantage of depositing graphene based nanostructures in the gas phase mode in comparison to deposition of graphene layer on metal substrate and formation of graphene-metal nanoparticles by multi step chemical and physical processes. In the present study metal-carbon nanoagglomerates were formed by spark generation process using metal ( $\mathrm{Cu}$ or $\mathrm{Pd})$ and carbon as the two electrodes. Metal and carbon concentration in the intermediate alloy/composite nanoparticle was thus fixed by the relative ablation rates of the two materials during spark generation step ${ }^{48}$. It might be possible to vary the metal-carbon composition by preparing metal agglomerates and then sintering them in the presence of carbon precursor gases (e.g. $\mathrm{CH}_{4}$ ). It is expected that this will result in a better control of number of graphene layers in the shell. Further, the M/MLG core shell nanoparticle prepared by the present method can also be incorporated into or onto growing thin films prepared by vacuum or plasma deposition techniques ${ }^{49}$. After etching the metal core, size-dependent electronic and magnetic properties of graphene shells can also be studied ${ }^{50}$. Moreover, the etching step for removing $\mathrm{Cu}$ or $\mathrm{Pd}$ core might be carried out in gas phase itself so that graphene shells can be deposited onto a desired substrate in the final step.

Synthesis of M/MLG nanoparticles having well defined dimensions and the possibility of their direct deposition on to different substrates will result in new and novel applications. MLG cap around the noble metal nanoparticles can result in significantly reducing the consumption of noble metals in large scale fuel cell applications ${ }^{11-13}$. Most recently, carbon-coated metal nanoparticles have shown exceptionally long term thermal and chemical stability against acidic erosion, reliable linking chemistry and biocompatibility, important for biomedical applications ${ }^{51}$. A well defined MLG shell can enhance the functionalization of drug molecules to metal nanoparticle core, which is useful in a number of drug delivery and bio imaging applications $^{52}$. The enhanced surface contact between metal and graphene layers is known to result in enhancing the $\mathrm{H}_{2}$ sensing response in graphene-Pd/Pt nanoparticles ${ }^{15,16}$. Graphene-metal (Au/Ag) nanoparticles with efficient molecule absorption property combined with strong surface enhanced Raman sensitivity are excellent substrates for nano-molar level molecular detection ${ }^{53,54}$. M/MLG nanoparticles may have superior electromagnetic interference shielding properties in comparison to individual metal or graphene layers ${ }^{55}$. M/MLG nanoparticles on solar cell surfaces may have superior antireflection properties due to anti-reflection (graphene layers) and surface plasmon (metal nanoparticles) effects ${ }^{20,56}$. SEM images of $\mathrm{Cu} / \mathrm{MLG}$ core shell nanoparticles deposited onto textured silicon substrates show possible uniform growth on substrates having non-planar surface using the present method.

\section{Methods}

The schematic diagram of the integrated gas phase setup used for growing $\mathrm{Cu} / \mathrm{MLG}$ and Pd/MLG core shell nanoparticles is shown in Fig. 1. It comprises of a spark generator for forming aerosol consisting of metal-carbon nanoagglomerates, particle charger for charging the agglomerates, DMA for selecting the agglomerates of constant mobility equivalent diameter (Dm), sintering furnace for compacting the agglomerates into M/MLG core shell nanoparticles and an ESP for depositing the M/ MLG core shell nanoparticles onto any desired substrate. In the spark generator, electrical sparks are generated by applying a pulsating high voltage $(\sim 3 \mathrm{kV})$ to the carbon and $\mathrm{Cu} / \mathrm{Pd}$ electrodes separated by a distance of $1.8 \mathrm{~mm}$ which is kept fixed during material ablation by an electrical stepper motor. Electrical sparks result in the ablation of the electrode material. Spark current controls the electrode ablation rate and can be changed by just varying the spark frequency. Due to very short duration of the pulsed discharge, evaporated material rapidly cools down, resulting in supersaturation, leading to the nucleation, condensation and finally to the formation of nanoagglomerates having a large size distribution. Average value of size and size distribution depends on the frequency and carrier gas flow. High purity nitrogen $\left(\mathrm{N}_{2}\right)$ (with $2 \%$ hydrogen) as a carrier gas is used in the complete process starting from the initial step of agglomerate formation to final step of nanoparticle deposition. In the particle charger, agglomerates were charged using a $\mathrm{Kr}-85$ based radioactive isotope. Particle charger is basically a radioactive $\mathrm{Kr}-85$ source which charges the nanoparticles both positively and negatively and is also called a neutralizer. DMA is used to 
select the nanoparticles as per their Dm values which are controlled by the flow conditions and voltage applied to the DMA electrodes. By measuring the size distribution of agglomerates just after the spark generator, frequency was adjusted to obtain the peak at the desired Dm value. In the in-flight sintering step, compaction, alloy formation and phase separation processes resulted in the formation of M/MLG core shell nanoparticles. Finally, M/MLG core shell nanoparticles were deposited onto the Si substrates and TEM grids for further characterization.

Three different $\mathrm{Pd}-\mathrm{C} / \mathrm{Cu}-\mathrm{C}$ agglomerates having $\mathrm{Dm}=35,52$ and $68 \mathrm{~nm}$ were selected using the DMA. Diameter of $\mathrm{C}$ and $\mathrm{Pd} / \mathrm{Cu}$ electrodes was kept fixed at $3.2 \mathrm{~mm}$. Spark frequency was kept constant at $200 \mathrm{~Hz}$ throughout the experiment. Carrier flow $\left(2 \% \mathrm{H}_{2}+98 \% \mathrm{~N}_{2}\right)$ in the spark generator and aerosol flow in the sintering furnace were kept fixed at $2.5 \mathrm{l} / \mathrm{m}$ and $1 \mathrm{l} / \mathrm{min}$, respectively. In the sintering furnace, agglomerates were sintered in-flight at $700^{\circ} \mathrm{C}, 820^{\circ} \mathrm{C}$ and $950^{\circ} \mathrm{C}$, respectively. In the ESP, a constant voltage of $1 \mathrm{KeV}$ was applied to the substrate with a fixed distance of $1.5 \mathrm{~mm}$ between the substrate and the nozzle.

TEM (FEI-Technai-G20 with a LaB6 filament, operated at $200 \mathrm{keV}$ ) was used to study the size and structural properties of nanoparticles. GAXRD (Philips X'Pert, PRO-PW 3040, CuK $\alpha$ ) measurements at a glancing angle of $1^{\circ}$ were carried out to investigate the structural properties. Micro-Raman measurements were performed to study the vibrational properties, using a Renishaw spectrometer at $514 \mathrm{~nm}$ of wavelength.

1. Du, X., Skachko, I., Barker, A. \& Andrei, E. Y. Approaching ballistic transport in suspended graphene. Nat Nano 3, 491-495 (2008).

2. Pati, S. K., Enoki, T. \& Rao, C. N. R. Graphene and Its Fascinating Attributes. (World Scientific, Singapore, 2011).

3. Balandin, A. A. Thermal properties of graphene and nanostructured carbon materials. Nat Mater 10, 569-581 (2011).

4. Lee, C., Wei, X., Kysar, J. W. \& Hone, J. Measurement of the elastic properties and intrinsic strength of monolayer graphene. Science 321, 385-388 (2008).

5. Miao, X. et al. High efficiency graphene solar cells by chemical doping. Nano Lett. 12, 2745-2750 (2012).

6. Schedin, F. et al. Detection of individual gas molecules adsorbed on graphene. Nat Mater 6, 652-655 (2007)

7. Scheuermann, G. M., Rumi, L., Steurer, P., Bannwarth, W. \& Mülhaupt, R. Palladium nanoparticles on graphite oxide and its functionalized graphene derivatives as highly active catalysts for the Suzuki-Miyaura coupling reaction. J. Am. Chem. Soc. 131, 8262-8270 (2009).

8. Li, Y. et al. Palladium nanoparticle-graphene hybrids as active catalysts for the Suzuki reaction. Nano Res. 3, 429-437 (2010).

9. Siamaki, A. R., Khder, A. E. R. S., Abdelsayed, V., El-Shall, M. S. \& Gupton, B. F. Microwave-assisted synthesis of palladium nanoparticles supported on graphene: A highly active and recyclable catalyst for carbon-carbon cross-coupling reactions. J. Catal. 279, 1-11 (2011).

10. Seger, B. \& Kamat, P. V. Electrocatalytically active graphene-platinum nanocomposites. role of 2-D carbon support in PEM fuel cells. J. Phys. Chem. C 113, 7990-7995 (2009).

11. Zhou, Y.-G., Chen, J.-J., Wang, F.-B., Sheng, Z.-H. \& Xia, X.-H. A facile approach to the synthesis of highly electroactive Pt nanoparticles on graphene as an anode catalyst for direct methanol fuel cells. Chem. Commun. 46, 5951-5953 (2010).

12. Zhao, H. et al. Fabrication of a palladium nanoparticle/graphene nanosheet hybrid via sacrifice of a copper template and its application in catalytic oxidation of formic acid. Chem. Commun. 47, 2014-2016 (2011).

13. Yang, J., Tian, C., Wang, L. \& Fu, H. An effective strategy for small-sized and highly-dispersed palladium nanoparticles supported on graphene with excellent performance for formic acid oxidation. J. Mater. Chem. 21, 3384-3390 (2011).

14. Ji, L. et al. Multilayer nanoassembly of Sn-nanopillar arrays sandwiched between graphene layers for high-capacity lithium storage. Energy Environ. Sci. 4, 3611-3616 (2011).

15. Johnson, J. L., Behnam, A., Pearton, S. J. \& Ural, A. Hydrogen sensing using Pdfunctionalized multi-layer graphene nanoribbon networks. Adv. Mater. 22, 4877-4880 (2010).

16. Kaniyoor, A., Imran Jafri, R., Arockiadoss, T. \& Ramaprabhu, S. Nanostructured Pt decorated graphene and multi walled carbon nanotube based room temperature hydrogen gas sensor. Nanoscale 1, 382-386 (2009).

17. Mao, S., Lu, G., Yu, K., Bo, Z. \& Chen, J. Specific protein detection using thermally reduced graphene oxide sheet decorated with gold nanoparticle-antibody conjugates. Adv. Mater. 22, 3521-3526 (2010).

18. Du, M., Yang, T. \& Jiao, K. Immobilization-free direct electrochemical detection for DNA specific sequences based on electrochemically converted gold nanoparticles/graphene composite film. J. Mater. Chem. 20, 9253-9260 (2010).

19. Li, X. et al. Large-area synthesis of high-quality and uniform graphene films on copper foils. Science 324, 1312-1314 (2009).

20. Kumar, R., Sharma, A. K., Bhatnagar, M., Mehta, B. R. \& Rath, S. Antireflection properties of graphene layers on planar and textured silicon surfaces. Nanotechnology 24, 165402 (2013)

21. Bai, S. \& Shen, X. Graphene-inorganic nanocomposites. RSC Advances 2, 64-98 (2012)

22. Shin, H.-J. et al. Efficient reduction of graphite oxide by sodium borohydride and its effect on electrical conductance. Adv. Funct. Mater. 19, 1987-1992 (2009).
23. Zan, R., Bangert, U., Ramasse, Q. \& Novoselov, K. S. Interaction of metals with suspended graphene observed by transmission electron microscopy. J. Phys. Chem. Lett. 3, 953-958 (2012).

24. Jiang, Y. et al. Facile electrochemical codeposition of “clean" graphene-Pd nanocomposite as an anode catalyst for formic acid electrooxidation. Electrochem. Commun. 19, 21-24 (2012).

25. Luo, Z. et al. Size-selective nanoparticle growth on few-layer graphene films. Nano Lett. 10, 777-781 (2010).

26. Zhou, H. et al. Thickness-dependent morphologies of gold on n-layer graphenes. J. Am. Chem. Soc. 132, 944-946 (2009).

27. Ruoff, R. S., Lorents, D. C., Chan, B., Malhotra, R. \& Subramoney, S. Single crystal metals encapsulated in carbon nanoparticles. Science 259, 346-348 (1993).

28. Majetich, S. A., Artman, J. O., McHenry, M. E., Nuhfer, N. T. \& Staley, S. W. Preparation and properties of carbon-coated magnetic nanocrystallites. Phys Rev B 48, 16845-16848 (1993).

29. Zalich, M. A., Baranauskas, V. V., Riffle, J. S., Saunders, M. \& St. Pierre, T. G. Structural and magnetic properties of oxidatively stable cobalt nanoparticles encapsulated in graphite shells. Chem. Mater. 18, 2648-2655 (2006).

30. Ma, Y. et al. Chemical functionalization of magnetic carbon-encapsulated nanoparticles based on acid oxidation. J. Phys. Chem. B 110, 20118-20122 (2006).

31. Yamamoto, T., Adachi, M., Kawabata, K., Kimura, K. \& Hahn, H. W. Palladium carbide nanoparticles by gas flow reaction synthesis. Appl. Phys. Lett. 63, 3020-3022 (1993).

32. Flanagan, T. B. \& Oates, W. A. The palladium-hydrogen system. Annu. Rev. Mater. Sci. 21, 269-304 (1991).

33. Smontara, A. et al. Structural (XRD and HRTEM) investigations of fullerite C60 and C70 samples. Mater. Sci. Eng., C 19, 21-25 (2002).

34. Hailstone, R. K., DiFrancesco, A. G., Leong, J. G., Allston, T. D. \& Reed, K. J. A study of lattice expansion in $\mathrm{CeO} 2$ nanoparticles by transmission electron microscopy. J. Phys. Chem. C 113, 15155-15159 (2009).

35. Sun, C. Q. Size dependence of nanostructures: Impact of bond order deficiency. Prog. Solid State Chem. 35, 1-159 (2007).

36. Sánchez-López, J. C. et al. Phase composition and tribomechanical properties of Ti-B-C nanocomposite coatings prepared by magnetron sputtering. J. Phys. D: Appl. Phys. 45, 375401 (2012).

37. Ferrari, A. C. \& Robertson, J. Interpretation of Raman spectra of disordered and amorphous carbon. Phys Rev B 61, 14095-14107 (2000).

38. Ferrari, A. C. Raman spectroscopy of graphene and graphite: Disorder, electronphonon coupling, doping and nonadiabatic effects. Solid State Commun. 143, 47-57 (2007).

39. Jerng, S. K. et al. Nanocrystalline graphite growth on sapphire by carbon molecular beam epitaxy. J. Phys. Chem. C 115, 4491-4494 (2011).

40. Calizo, I., Bejenari, I., Rahman, M., Liu, G. \& Balandin, A. A. Ultraviolet Raman microscopy of single and multilayer graphene. J. Appl. Phys. 106, 043509-043505 (2009).

41. Das, A. et al. Monitoring dopants by Raman scattering in an electrochemically top-gated graphene transistor. Nat Nano 3, 210-215 (2008).

42. López, G. A. \& Mittemeijer, E. J. The solubility of C in solid Cu. Scr. Mater. 51, 1-5 (2004).

43. Okamoto, H. C-Pd (Carbon-Palladium). J. Phase. Equ. Diff. 28, 313 (2007).

44. Skriver, H. L. \& Rosengaard, N. M. Surface energy and work function of elemental metals. Phys Rev B 46, 7157-7168 (1992).

45. Papirer, E., Brendle, E., Ozil, F. \& Balard, H. Comparison of the surface properties of graphite, carbon black and fullerene samples, measured by inverse gas chromatography. Carbon 37, 1265-1274 (1999).

46. Mattevi, C., Kim, H. \& Chhowalla, M. A review of chemical vapour deposition of graphene on copper. J. Mater. Chem. 21, 3324-3334 (2011).

47. Heurlin, M. et al. Continuous gas-phase synthesis of nanowires with tunable properties. Nature 492, 90-94 (2012).

48. Tabrizi, N. S., Ullmann, M., Vons, V. A., Lafont, U. \& Schmidt-Ott, A. Generation of nanoparticles by spark discharge. J. Nanopart. Res. 11, 315-332 (2009).

49. Kala, S., Mehta, B. R. \& Kruis, F. E. A dual-deposition setup for fabricating nanoparticle-thin film hybrid structures. Rev. Sci. Instrum. 79, 013902-013907 (2008).

50. Potasz, P., Güçü, A. D., Voznyy, O., Folk, J. A. \& Hawrylak, P. Electronic and magnetic properties of triangular graphene quantum rings. Phys Rev B 83, 174441 (2011).

51. Herrmann, I. K., Grass, R. N. \& Stark, W. J. High-strength metal nanomagnets for diagnostics and medicine: carbon shells allow long-term stability and reliable linker chemistry. Nanomedicine 4, 787-798 (2009).

52. Lu, A.-H., Salabas, E. L. \& Schüth, F. Magnetic nanoparticles: synthesis, protection, functionalization, and application. Angew. Chem. Int. Ed. 46, 1222-1244 (2007).

53. Lu, G. et al. Surface enhanced Raman scattering of Ag or Au nanoparticledecorated reduced graphene oxide for detection of aromatic molecules. Chem. Sci. 2, 1817-1821 (2011).

54. Wang, Y. et al. Gold on graphene as a substrate for surface enhanced Raman scattering study. Appl. Phys. Lett. 97, 163111-163113 (2010).

55. Hong, S. K. et al. Electromagnetic interference shielding effectiveness of monolayer graphene. Nanotechnology 23, 455704 (2012). 
56. Atwater, H. A. \& Polman, A. Plasmonics for improved photovoltaic devices. Nat Mater 9, 205-213 (2010).

\section{Acknowledgements}

The support provided by Nanomission Programme of Department of Science and Technology, Department of Electronic and Information Technology, Government of India and Schlumberger Chair Professorship is acknowledged. One of the authors S.K.S. is thankful to Council of Scientific and Industrial Research, India for providing senior research fellowship.

\section{Author contributions}

S.K.S. carried out the majority of the research work towards synthesis and characterization of graphene-metal nanoparticles. R.K. carried out the electrical and optical measurements.

V.S. assisted in the synthesis of nanoparticles on different substrates. The present study was conceived and supervised by B.R.M., Schlumberger Chair Professor, Thin Film Laboratory, Physics Department, I. I. T. Delhi, New Delhi, India.

\section{Additional information}

Supplementary information accompanies this paper at http://www.nature.com/ scientificreports

Competing financial interests: The authors declare no competing financial interests.

How to cite this article: Sengar, S.K., Mehta, B.R., Kumar, R. \& Singh, V. In-flight gas phase growth of metal/multi layer graphene core shell nanoparticles with controllable sizes. Sci. Rep. 3, 2814; DOI:10.1038/srep02814 (2013)

(c) (i) $(-)$ This work is licensed under a Creative Commons Attribution-

BY NC ND NonCommercial-NoDerivs 3.0 Unported license. To view a copy of this license, visit http://creativecommons.org/licenses/by-nc-nd/3.0 